\title{
The Frequency of Iron Deficiency among Patients with Hemophilia
}

\author{
Paranthaman Poongavanam ${ }^{1}$, Jayaprakash Nandakumaran ${ }^{2}$, \\ Malathi Shanmugam ${ }^{2}$, Hmingmuanpuii Pachuau ${ }^{3}$ \\ ${ }^{1}$ Professor, ${ }^{2}$ Assistant Professor, \\ ${ }^{3}$ Junior Resident, Department of Medicine, Government Royapettah Hospital/Kilpauk Medical College, \\ Chennai, Tamil Nadu, India.
}

\begin{abstract}
Background: Haemophilia is a rare inherited X-linked recessive disorder characterized by deficiency of Factor VIII or Factor IX coagulant activity required for generation of Thrombin in the Intrinsic pathway of coagulation. India has the second highest haemophilia burden in the world. With increase in severity of the disease, patients experience increased frequency of spontaneous bleed. Iron deficiency is expected in these vulnerable population due either to presence of occult blood loss in urine/stool or deposition of iron in synovial membrane during repeated bleeding episodes.

Materials and Methods: Our study population were patients confirmed with Factor VIII/IX deficiency attending Government Royapettah Hospital. We further classify them as having Mild(6-40\%), Moderate(1$5 \%)$,Severe $(<1 \%)$ according to their factor activity level. Haemoglobin, Peripheral Smear \& serum Ferritin levels were evaluated. The correlation of serum ferritin with severity of disease was established.

Results: Out of 50 patients, 46(92\%) were haemophilia A and 4(8\%) were haemophilia B; 39(78\%) were patients with severe form of disease, out of which 4(8\%) were Inhibitor positive status. 36(72\%) had haemoglobin $<13 \mathrm{mg} / \mathrm{dl}$ while $14(28 \%)$ had value $>13 \mathrm{mg} / \mathrm{dl}$. Peripheral smear showed microcytic hypochromic picture in 34(68\%) while 16(32\%) showed normal blood picture. The lowest Ferritin level observed was $21 \mathrm{ng} / \mathrm{ml}$ with highest being $89 \mathrm{ng} / \mathrm{ml}$. The mean ferritin level was within the lower limits of normal in all the patients.

Conclusion : Iron deficiency is common among patients with haemophilia \& more so with increase severity of the disease due to increase frequency of spontaneous bleed. As iron deficiency is known to have adverse effect on wound healing, immunity \& mental well-being, these combined factors could perpetuate the vicious cycle of joint bleed and iron deficiency, proper guidelines regarding screening of iron deficiency should be established $\&$ attempts made for correction by iron/dietary supplementation. Other factors like intestinal infestation and dietary habits must also be taken into account.
\end{abstract}

Keywords: Haemophilia, iron deficiency, serum ferritin, severe disease.

\section{Introduction}

Haemophilia is a group of hereditary X-linked recessive disorder characterised by deficiency of factor VIII or IX coagulant activity [1]. It is the most common congenital bleeding encountered in clinical practice affecting men, whereas females are usually carriers [2]. Depending on the level of factor activity, it is further classified as Mild (6-40\%), Moderate (1-5\%) and Severe (<1\%) [3]. India has the second highest haemophilia burden in the world. Bleeding can occur anywhere from the body. The common sites are into joints and muscles and from the gastrointestinal tract. Approximately $80 \%$ of haemorrhage occurs in the joints; the ankles are most commonly affected in children, and the knees, elbows, and ankles in adolescents and adult. Spontaneous hemarthroses are characteristic of severe disease. Iron deficiency might add on to the morbidity in Haemophiliacs. The iron deficiency can be due to the presence of occult blood loss in the urine and stools or due to the deposition of iron in the synovial membrane during repeated bleeding episodes [4]. Also, concurrent parasitic infestation, which is a common entity, may contribute to the iron deficiency [5].

Identifying iron deficiency and treating it in these patients might help to improve their quality of living. Iron deficiency could be assessed by doing simple blood investigations like Serum Ferritin. Ferritin is an intracellular protein that store iron in a non-toxic form, to deposit in a safe form and to transport to areas where it is required [6]. In the settings of anaemia, low serum ferritin is the most specific laboratory test for iron deficiency [7]. Confirmation could be done using bone marrow studies but it is an invasive procedure which is not without risk especially in patients with bleeding disorders. Limited studies are available on the subject, and hence an insight into the frequency of iron deficiency among haemophilia is necessary, which if detected could be easily corrected and would improve the outcome of the patient. 


\section{Materials And Methods}

The study was conducted at Government Royapettah Hospital, Chennai for a period of six months. We proceeded with the procedures after getting informed written consent from Patients or their legal guardian in case of younger patients after obtaining clearance from the Ethical Committee of Government Kilpauk Medical College \& Hospital Chennai.

Study design: Cross-sectional study.

Study population: It included 50 cases of Haemophilia A (46) \& Haemophilia B (4) confirmed using Factor Assays, attending Government Royapettah Hospital.

\section{Inclusion criteria:}

Patients with haemophilia A or haemophilia B

\section{Exclusion criteria:}

Bleeding disorders other than haemophilia.

Patients with fever or any evidence of infection

Patients with blood transfusion in the last 3 months

\section{Methodology:}

After getting written informed consent from either the patient or legal guardian, history was obtained regarding the type of haemophilia, severity of disease from factor levels ,any history of fever or obvious infections, recent transfusion of blood products. Blood was drawn and sent for laboratory investigations like Haemoglobin levels, serum ferritin levels and peripheral smear. The results obtained were then analysed to identify iron deficiency. Serum ferritin concentration is proportional to the amount of iron in the body.

It was measured using immunoassay method.

Step 1 - The binding of human serum ferritin to a solid phase antihuman ferritin and the simultaneous binding of the purified antihuman ferritin conjugated with ALP to the insoluble immune complex.

Step 2 - Reaction of ALP with a substrate solution consisting of phenyphosphate disodium and 4-amino antipyrine. Following the addition of potassium ferricyanide a colour develops, the optical density (490-510nm) of which is directly proportional to the ferritin in the sample.

\section{Statistical Analysis}

The data obtained was analysed using the SSPS software.

Table 1: Distribution of type of haemophilia

\begin{tabular}{|c|l|l|l|l|}
\hline & Frequency & Percent & Valid Percent & Cumulative Percent \\
\hline Valid & 40 & 80.0 & 80.0 & 80.0 \\
Haemophilia A & 6 & 12.0 & 12.0 & 92.0 \\
$\begin{array}{c}\text { Haemophilia B } \\
\text { with inhibitor positive } \\
\text { Total }\end{array}$ & 4 & 8.0 & 8.0 & 100.0 \\
\hline
\end{tabular}

Of the study population,

$80 \%$ were Haemophilia A

$6 \%$ were Haemophilia B

$4 \%$ had positive inhibitors to Factor VIII

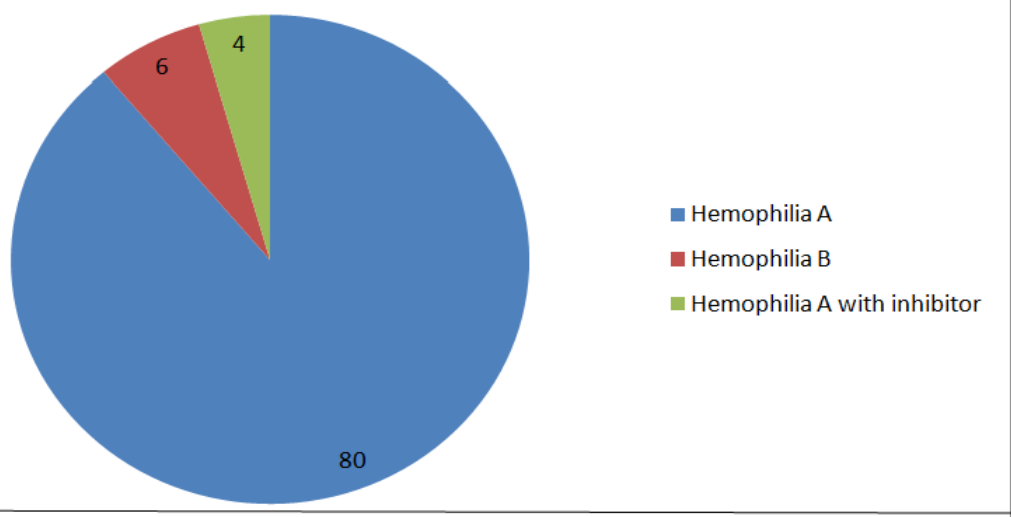

Figure 1: Pie-chart showing distribution of type of haemophilia. 
Table 2: Severity of Haemophilia

\begin{tabular}{|ll|l|l|l|l|}
\hline & Frequency & Percent & Valid Percent & Cumulative Percent \\
\hline Valid & Mild & 6 & 12.0 & 12.0 & 12.0 \\
& Moderate & 5 & 10.0 & 10.0 & 22.0 \\
& Severe & 35 & 70.0 & 70.0 & 92.0 \\
Severe with inhibitors & 4 & 8.0 & 8.0 & 100.0 \\
& Total & 50 & 100.0 & 100.0 & \\
\hline
\end{tabular}

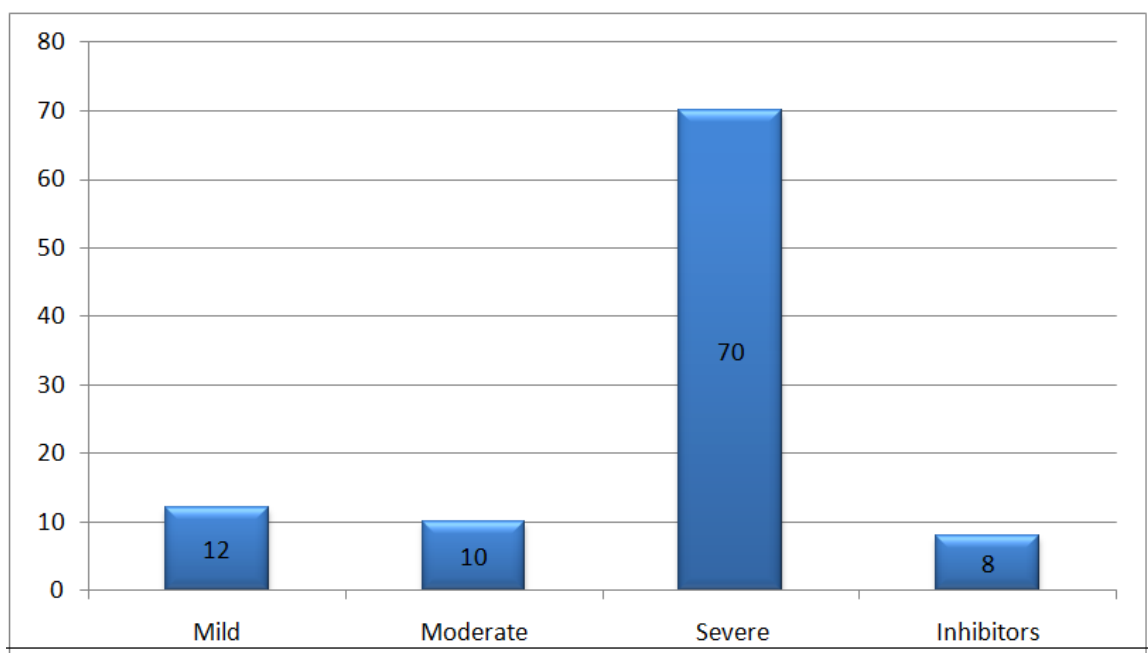

Figure 2: Bar diagram showing the percentage distribution of patients according to severity of disease

Table 3: Analysis of Haemoglobin

\begin{tabular}{|c|c|c|c|c|c|}
\hline & & Frequency & Percent & $\begin{array}{l}\text { Valid } \\
\text { Percent }\end{array}$ & Cumulative Percent \\
\hline Valid & $\begin{array}{l}\mathrm{Hb}>13 \mathrm{mg} / \mathrm{dl} \\
\mathrm{Hb}<13 \mathrm{mg} / \mathrm{dl} \\
\text { Total }\end{array}$ & $\begin{array}{l}14 \\
36 \\
50\end{array}$ & $\begin{array}{r}28.0 \\
72.0 \\
100.0\end{array}$ & $\begin{array}{r}28.0 \\
72.0 \\
100.0\end{array}$ & $\begin{array}{l}28.0 \\
100.0\end{array}$ \\
\hline
\end{tabular}

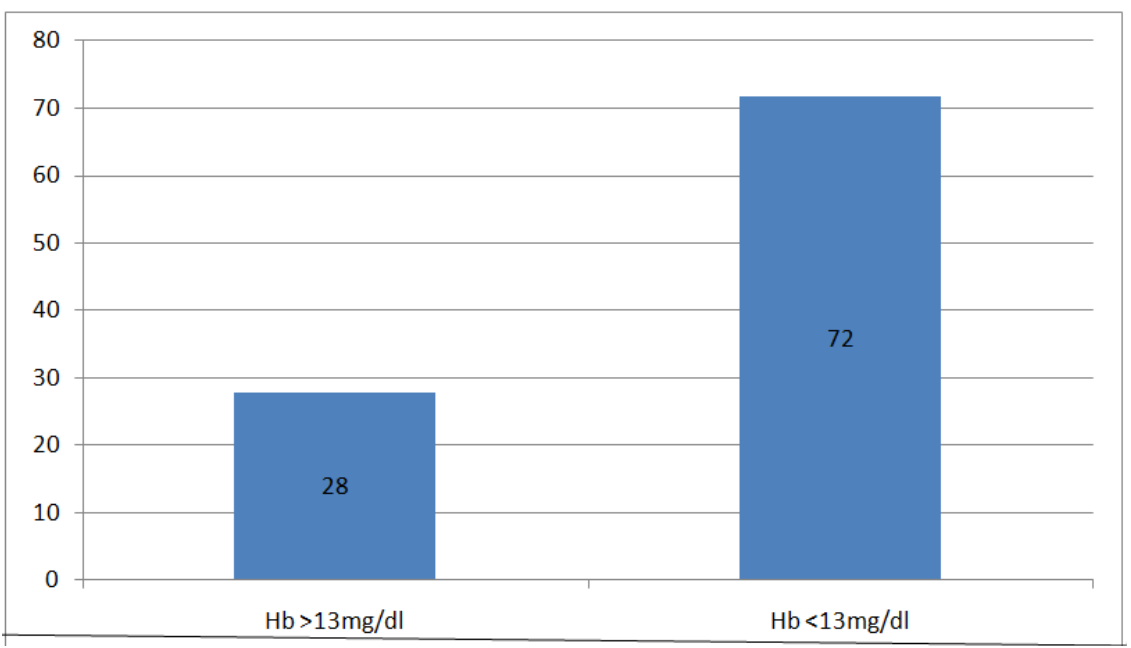

Figure 3: Bar diagram showing percentage of patients with haemoglobin levels more than or less than $13 \mathrm{mg} / \mathrm{dl}$.

The result analysis showed that $72 \%$ had $\mathrm{Hb}$ level of less than $13 \mathrm{mgs} / \mathrm{dl}$. Only $28 \%$ had a value greater than $13 \mathrm{mgs} / \mathrm{dl}$. The mean haemoglobin in the study population was $12.18 \mathrm{mgs} / \mathrm{dl}$.

Table 4: Analysis of Peripheral smear

\begin{tabular}{|c|l|l|l|l|}
\hline & Frequency & Percent & Valid Percent & Cumulative Percent \\
\hline $\begin{array}{c}\text { Valid } \\
\begin{array}{c}\text { Microcytic } \\
\text { hypochromic } \\
\text { Normal } \\
\text { Total }\end{array}\end{array}$ & 34 & 68.0 & 68.0 & 68.0 \\
\hline 50 & 32.0 & 32.0 & 100.0 \\
\hline
\end{tabular}




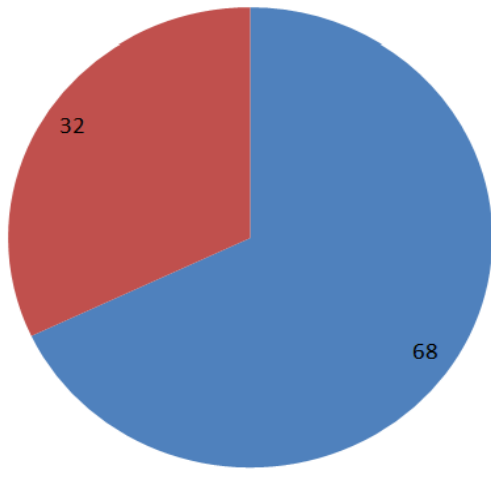

- Microcytic hypochromic

- Normal

Figure 4: Pie-chart depicting percentage of patients with and without microcytic hypochromic peripheral smear.

The results of peripheral smear analysis showed,

$\square 32 \%$ had a normal peripheral smear

$\square 68 \%$ had a peripheral smear with microcytic hypochromic picture.

Table 5: Serum ferritin level

\begin{tabular}{|l|l|l|l|l|l|}
\hline & N & Mean & Std.Deviation & Minimum & Maximum \\
\hline & & & & & \\
Mild A & 3 & 54.100 & 14.8987 & 37.7 & 66.8 \\
Mild B & 3 & 58.167 & 12.2712 & 44.0 & 65.5 \\
Moderate A & 5 & 48.200 & 11.4140 & 34.0 & 64.0 \\
Severe A & 32 & 51.091 & 19.1329 & 21.0 & 89.0 \\
Severe B & 3 & 51.800 & 18.2000 & 32.0 & 67.8 \\
Severe A with inhibitor & 4 & 51.150 & 22.6530 & 22.0 & 72.6 \\
Total & 50 & 51.454 & 17.5141 & 21.0 & 89.0 \\
\hline
\end{tabular}

Results showed the mean Ferritin in,

$\square$ Mild haemophilia A was $54 \mathrm{ng} / \mathrm{ml}$.

$\square$ Mild Haemophilia B was 58.16ng/ml.

Moderate Haemophilia A was $48.2 \mathrm{ng} / \mathrm{ml}$.

Severe Haemophilia A was $51.09 \mathrm{ng} / \mathrm{ml}$

Severe Hemophilia A with inhibitors was $51.15 \mathrm{ng} / \mathrm{ml}$.

$\square$ Severe Haemophilia B was $51.8 \mathrm{ng} / \mathrm{ml}$.

Table 6: Analysis of severity of haemophilia and serum ferritin level

\begin{tabular}{|l|c|l|l|}
\hline Severity of Haemophilia & Serum Ferritin (ng/ml) & Total \\
\hline \multirow{3}{*}{ Mild Haemophilia(A+B) } & $<50$ & $50-100$ & \multirow{3}{*}{$6(100 \%)$} \\
\cline { 2 - 3 } Moderate Haemophilia & $2(33.3 \%)$ & $4(66.7 \%)$ & $5(100 \%)$ \\
Severe Haemophilia (A+B) & $3(60 \%)$ & $2(40 \%)$ & $35(100 \%)$ \\
Severe Haemophilia with Inhibitor & $21(60 \%)$ & $14(40 \%)$ & $4(100 \%)$ \\
\hline
\end{tabular}

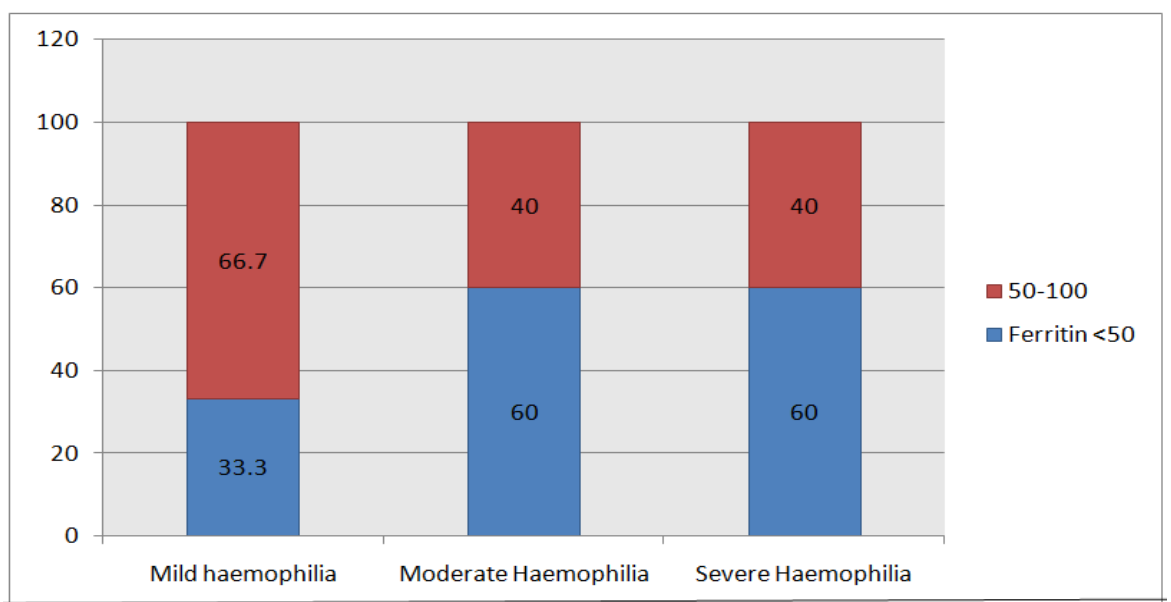

Figure 5: Bar diagram showing the correlation between severity of haemophilia and serum Ferritin Level. 


\section{Discussion}

Our study population comprised of 50 haemophilia patients with majority being Haemophilia $\mathrm{A}(84 \%)$ and majority have severe form of the disease(78\%). Patients with Haemophilia A or B are clinically indistinguishable. Bleeding may occur anywhere in patients with haemophilia. Approximately $80 \%$ of haemorrhage occurs in the joints. Spontaneous hemarthroses are characteristic of severe disease. Thrombin formation is markedly impaired in haemophilia [8] hence; a stable hemostatic plug needed to arrest the bleeding is not formed. The structure of hemostatic plugs in haemophiliacs are characterized by defective stabilization of initial platelet rich plug in a fibrin meshwork [9][10]. The fibrin formed under these condition are thus abnormal structure with increased permeability and decreased mechanical strength [11][12]. In addition, haemophilia patients have impaired wound healing as adequacy \& stability of initial fibrin clot is an important determinant of wound healing[13]. Haemophilia patients are expected to have iron deficiency due to repeated bleeding episodes. With repeated bleeding, there is deposition of iron in synovial membrane. However the iron deposits are not physiologically functional as they are not readily available for haemoglobin synthesis but rather are pathological mediators of inflammatory changes leading to crippling synovitis and arthropathy [14].

Iron deposits serve as a stimuli for delayed macrophage influx. Macrophage releases range of mediators involved in inflammation and angiogenesis and normally play a role in removing debris from site of injury [15]. After internalization of haemoglobin by the macrophages, free iron gets released from haemoglobin which then primarily binds to Ferritin, an intra-cellular protein which stores iron in a non-toxic form.

While iron can clearly have direct toxic effects on tissues, it also modulates inflammatory and immune functions. Haemophilic joint accumulates iron much more and longer than normal population, excess tissue iron is thought to play a role in synovitis and excess angiogenesis [15]. These newly formed vessels are more vulnerable to bleed.Iron impairs wound healing through number of mechanisms which include dysregulation of hypoxia-inducible factor expression, decreased lactoferrin mediated cell proliferation and alteration of collagen synthesis [16] In addition, iron deficiency has been shown to significantly impair immune response [17] and is associated with adverse cognitive and psychological effects which can lead to attention deficit, social withdrawal and poor intellectual attainment[18]

Iron studies has not been adequately studied in haemophilia patients. In developing countries where due to poor sanitary conditions there is high incidence of intestinal infestation, occult blood loss through gastrointestinal tract could also be an important contributing factor to iron deficiency. Serum ferritin although considered to be most specific test for iron deficiency in settings of iron deficiency anemia[7] may be raised in condition with iron excess as in hemochromatosis, macrophage activation syndrome, hemophagocytic lymphohistiocytosis. It is an acute phase reactant so maybe raised in any acute inflammation/infection; in these condition a normal C-reactive protein would exclude elevated ferritin due to acute phase reaction. Low levels may be observed in hypothyroidism, vitamin $\mathrm{C}$ deficiency or celiac disease.

Our study shows mean ferritin level within normal limits but are all in the lower range of normal. Other serum iron studies might be helpful to aid in the diagnosis of Iron deficiency. A study done in Haemophilia A patients in Northern Nigeria found that higher frequency of iron deficiency in severe disease as compared to non-severe disease[19]. On the other hand, we observed, as the factor level decreased from Mild to Moderate there is proportional decrease in ferritin level but in those with severe disease we observed there is increase in ferritin level in contrary to other study (Ahmed Et.al). The possible explanation for this increase in ferritin level among severe haemophilia could be, because of acute presentation in severe disease as a part of acute phase reactants, the serum ferritin could have been elevated but also we should consider possibility of underlying infection which has to be ruled out by looking into other laboratory tests like C-reactive protein/Erythrocyte sedimentation rate. We also found patients with severe haemophilia A with inhibitors also had elevated ferritin levels suggesting, with more severe the factor deficiency there is a possibility of increase serum ferritin level as a part of acute phase reaction. Maybe in the future all these tests could be done to rule out other factors influencing raised in serum ferritin level. Also, larger sample size with equal distribution of patients within each sub-group of severity of disease might be helpful to obtain a better result. Given the huge impact of iron deficiency and the vulnerability of haemophilia patients, proper guidelines regarding screening of iron deficiency should be established \& attempts made for correction by iron/dietary supplementation or through proper health educations regarding dietary and sanitary conditions.

\section{Conclusion}

Haemophilia patients are prone to develop iron deficiency due to repeated bleeding, more so in those with severe form of the disease. In our study, it was observed that patients with severe form of haemophilia had lower levels of haemoglobin with microcytic hypochromic peripheral smear picture and serum ferritin levels within lower limits of normal. Iron plays important role in wound healing, immunity and mental development which if not detected and treated could result in crippling arthropathy affecting the quality of life of patients. Hence efforts must be made to correct iron deficiency by means like dietary supplementation, iron 
supplementation (keeping in mind its side effects), de-worming and avoidance of certain activities which would increase the frequency of joint bleed.

\section{References}

[1]. Srivastava A, Tariq M, Heijnen L. Haemophilia in developing countries-the challenge of detection and diagnosis. In: Comprehensive Haemophilia Care in Developing Countries. Ch. 2. Lahore: Feroz Sons (Pvt) Ltd.; 2012. p. 17-25.

[2]. Scott JP, Montgomery RR. Hemorrhagic and thrombotic disorder. In: Kliegman RM, Behrman RE, Jenson BF, editors. Nelson's Text Book of Pediatrics. 18 th ed., Vol. 20. Philadelphia: Saunder; 2010. p. 61-88.

[3]. Tantawy AAG. Molecular genetics of haemophilia-A: clinical perspectives. Egypt J Med Hum Genet $2010 ; 11$ :105-114.

[4]. Arch Pathol Lab Med. 1981 Dec; 105(12):655-8.

Iron studies in haemophilia.

[5]. Lottenberg R, Kitchens CS, Roessler GS, Noyes WD.

[6]. Umma A Ibrahim, Sagir G Ahmed, Modu B Kagu, Usman A Abjah. Impact of intestinal helminths on the risk of gastrointestinal haemorrhage and iron deficiency among haemophilia patients in northern Nigeria. J Haem Pract 2017;4(1).

[7]. Seckback J (1982). "Ferreting out the secrets of plant ferritin - A review". Journal of Plant Nutrition. 5 (4-7): 369-394.

[8]. Guyatt GH, Patterson C, Ali M, Singer J, Levine M, Turpie I, Meyer R (March 1990).'Diagnosis of iron deficiency in the elderly". The American Journal of Medicine. 88 (3):205-9.

[9]. Hoffman M, Monroe DM $3{ }^{\text {rd }}$. A cell-based model of hemostasis. Thromb Haemost. 2001;85: 958-965.

[10]. Vander Velden P, Giles AR. A detailed morphological evaluation of the evolution of the haemostatic plug in normal,factor VII and factor VIII deficient dogs. Br J Haematol.1988;70: 345-355.

[11]. Sixma JJ,van den Berg A. The haemostatic plug in haemophilia A: a morphological study of haemostatic plug formation in bleeding time skin wounds of patients with severe haemophilia A. Br J Haematol. 1984;58:741-753.

[12]. He S, Blomback M, Jacobsson Ekman G, Hedner U. The role of recombinant factor VIIa (FVIIa) in fibrin structure in the absence of. FVIII/FIX. J Thromb Haemost 2003; 1: 1215-9.

[13]. Wolberg AS, Allen GA, Monroe DM, Hedner U, Roberts HR, Hoffman. M. High dose factor VIIa improves clot structure and stability in a model of haemophilia B. Br J Haematol.2005;131:645-655.

[14]. Hoffman M, Harger A, Lenkowski A, Hedner U, Roberts HR, Monroe DM. Cutaneous wound healing is impaired in hemophilia B. Blood 2006; $108: 3053-3060$.

[15]. Nieuwenhuizen L, Schutgens RE, van Asbeck BS, Wenting MJ, van Veghel K, Roosendaal G, et al. Identification and expression of iron regulators in human synovium: evidence for upregulation in haemophilic arthropathy compared to rheumatoid arthritis, osteoarthritis, and healthy controls. Haemophilia 2013; 19 :e218-e227.

[16]. DiPietro LA. Wound healing the role of the macrophage and other immune cells. Shock 1995;4:233-240.

[17]. Wright JA, Richards T, Srai SK. The role of iron in the skin and cutaneous wound healing. Front Pharmacol $2014 ; 5: 156$.

[18]. Ekiz C, Agaoglu L, Karakas Z, Gurel N, Yalcin I. The effect of iron deficiency anemia on the function of the immune system. Hematol J 2005; 5 :579-583.

[19]. Halterman JS, Kaczorowski JM, Aligne CA, Auinger P, Szilagyi PG. Iron deficiency and cognitive achievement among schoolaged children and adolescents in the United States. Pediatrics 2001; $107: 1381-1386$.

[20]. Ahmed SG, Kagu MB, Ibrahim UA, Bukar AA. The frequency of iron deficiency among patients with haemophilia-A in northern Nigeria: correlation with the disease severity and clinical implications. Egypt J Haematol 2015;40:85-9. 